\title{
Fractionation of Spatial Memory in GRM2/3 (mGlu2/mGlu3) Double Knockout Mice Reveals a Role for Group II Metabotropic Glutamate Receptors at the Interface Between Arousal and Cognition
}

\author{
Louisa Lyon', Philip WJ Burnet', James NC Kew², Corrado Corti ${ }^{3}$, J Nicholas P Rawlins ${ }^{4}$, Tracy Lane', \\ Bianca De Filippis ${ }^{5}$, Paul J Harrison*,1 and David M Bannerman*,4 \\ 'Department of Psychiatry, University of Oxford, Warneford Hospital, Oxford, UK; ${ }^{2}$ Neurosciences CEDD, GlaxoSmithKline, New Frontiers \\ Science Park, Harlow, UK; ${ }^{3}$ Neurosciences CEDD, GlaxoSmithKline, Verona, Italy; ${ }^{4}$ Department of Experimental Psychology, University of Oxford, \\ Oxford, UK; ${ }^{5}$ Section of Behavioral Neuroscience, Department of Cell Biology and Neuroscience, Instituto Superiore di Sanita, Rome, Italy
}

Group II metabotropic glutamate receptors (mGluR2 and mGluR3, encoded by GRM2 and GRM3) are implicated in hippocampal function and cognition, and in the pathophysiology and treatment of schizophrenia and other psychiatric disorders. However, pharmacological and behavioral studies with group II mGluR agonists and antagonists have produced complex results. Here, we studied hippocampus-dependent memory in GRM2/3 double knockout (GRM2/3 ${ }^{-1-}$ ) mice in an iterative sequence of experiments. We found that they were impaired on appetitively motivated spatial reference and working memory tasks, and on a spatial novelty preference task that relies on animals' exploratory drive, but were unimpaired on aversively motivated spatial memory paradigms. GRM2/3 ${ }^{-1-}$ mice also performed normally on an appetitively motivated, non-spatial, visual discrimination task. These results likely reflect an interaction between GRM2/3 genotype and the arousal-inducing properties of the experimental paradigm. The deficit seen on appetitive and exploratory spatial memory tasks may be absent in aversive tasks because the latter induce higher levels of arousal, which rescue spatial learning. Consistent with an altered arousal-cognition relationship in GRM2/3-1- mice, injection stress worsened appetitively motivated, spatial

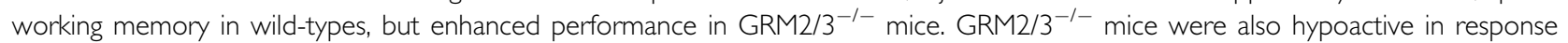
to amphetamine. This fractionation of hippocampus-dependent memory depending on the appetitive-aversive context is to our knowledge unique, and suggests a role for group II mGluRs at the interface of arousal and cognition. These arousal-dependent effects may explain apparently conflicting data from previous studies, and have translational relevance for the involvement of these receptors in schizophrenia and other disorders.

Neuropsychopharmacology (20II) 36, 26I6-2628; doi: I0.1038/npp.20II.I45; published online I0 August 20II

Keywords: hippocampus; schizophrenia; metabotropic glutamate receptor; arousal

\section{INTRODUCTION}

Group II metabotropic glutamate receptors (mGluRs) comprise mGluR2 (also called mGlu2), encoded by GRM2, and mGluR3 (mGlu3), encoded by GRM3. They are grouped together on the basis of sequence homology and a shared signal transduction mechanism, coupling via $G_{o}$ and $G_{i}$ proteins to inhibit adenylate cyclase (Niswender and Conn,

*Correspondence: PJ Harrison, Department of Psychiatry, University of Oxford, Warneford Hospital, Oxford OX3 7JX, UK, Tel: + 441865 223730, Fax: + 441865 251076, E-mail: paul.harrison@psych.ox.ac.uk or DM Bannerman, Department of Experimental Psychology, University of Oxford, South Parks Road, Oxford OXI 3UD, UK, E-mail: david.bannerman@psy.ox.ac.uk

Received 15 December 2010; revised 8 May 2011; accepted 21 June 2011
2010). mGlu2 receptors are neuronal, particularly in the pre-terminal regions of axons, away from the active zone of neurotransmitter release, whereas mGlu3 receptors are found both pre- and postsynaptically, and in glia. A key function of the presynaptic group II mGluRs is to inhibit neurotransmitter release, and mGluR2s primarily act as autoreceptors that negatively modulate glutamate release (Cartmell and Schoepp, 2000; Schoepp, 2001).

Group II mGluRs are being studied for their involvement in, and as potential treatment targets for, a range of psychiatric conditions including schizophrenia, anxiety and stress-related disorders, and substance misuse (Swanson et al, 2005; Witkin and Eiler, 2006; Markou 2007; Krystal et al, 2010). Their putative involvement in cognition and schizophrenia was stimulated by the seminal paper by Moghaddam and Adams (1998). These investigators showed that an mGluR2/3 agonist, LY354740, reversed a spatial 
working memory (SWM) deficit in rats, which had been produced by the NMDA receptor antagonist, phencyclidine (PCP). Krystal et al (2005) described comparable findings in human subjects and, notably, Patil et al, (2007) reported that an mGluR2/3 agonist was an effective antipsychotic in a clinical trial. Although unconfirmed, this study has encouraged further investigations of this therapeutic approach and its underlying rationale. In parallel, evidence has emerged that allelic variation in GRM3 affects human hippocampal function and activation (Egan et al, 2004; de Quervain and Papassotiropoulos, 2006), probably via genotype effects on glutamatergic transmission (Egan et al, 2004; Marenco et al, 2006). There is also modest evidence that GRM3 may be a gene for schizophrenia, in its own right or via epistatic and gene-environment interactions (Egan et al, 2004; Nicodemus et al, 2007; see Harrison et al, 2008). Finally, the expression and function of mGlu2 and mGlu3 may be altered in the disorder (eg, Gupta et al, 2005; Gonzalez-Maeso et al, 2008; Sartorius et al, 2008; Ghose et al, 2009).

Together, these studies suggest that group II mGluRs are involved in cognition and in psychosis (Moghaddam, 2004; Moreno et al, 2009; Krystal et al, 2010). However, many uncertainties remain, not least since pharmacological studies in rodents aimed at elucidating the role of mGluR2/3 in hippocampus-dependent cognition have revealed a varied picture. Thus, in contrast to the improvement in SWM seen with an mGluR2/3 agonist in PCP-treated animals (Moghaddam and Adams 1998), mGluR2/3 agonists impair performance on this task when administered to non-pretreated rodents (Aultman and Moghaddam, 2001; Gregory et al, 2003) or non-human primates (Spinelli et al, 2005). The effects of mGluR $2 / 3$ antagonists on hippocampus-dependent memory tasks are also varied: LY341495 produced a small improvement in both T-maze SWM (Gregory et al, 2003) and spatial reference memory (SRM) in the Morris water maze (Higgins et al, 2004), whereas performance on a passive avoidance task was impaired (Sato et al, 2004). Moreover, other studies have found no effect of mGluR2/3 ligands on cognitive tasks (eg, Schlumberger et al, 2009; Amitai and Markou, 2010). This complex pattern of results suggest that the effects of mGlu2/ 3 on cognition may be sensitive to various factors (eg, glutamatergic 'tone', previous experience, or the nature of the task chosen), but the matter has not been clearly explored.

Mice lacking GRM2 (GRM2 ${ }^{-1-}$ mice) or GRM3 (GRM3 ${ }^{-1-}$ mice) provide a complementary means to assess the roles of these receptors, but although they have been studied in various domains, assessment of hippocampus-dependent cognition has been limited to a report that GRM2 ${ }^{-1-}$ mice perform normally in the water maze (Yokoi et al, 1996). In any event, the phenotype of GRM2 $2^{-1-}$ and $\mathrm{GRM}^{-1-}$ mice may be affected by a degree of redundancy between these two homologous receptors and the possibility of compensatory changes. Indeed, a small but significant increase in GRM2 expression is observed in the hippocampus of $\mathrm{GRM}^{-1-}$ mice and vice versa (Lyon et al, 2008). Here, we have studied double knockout mice in which both GRM2 and GRM3 have been deleted (GRM2/3 ${ }^{-1-}$ mice), precluding such compensation. Using an iterative series of experiments, we found that GRM $2 / 3^{-I-}$ mice display a striking fractionation of hippocampus-dependent spatial memory, with impaired performance on appetitive and spontaneous/exploratory spatial memory tasks but normal performance on equivalent aversive tasks. We present evidence that the observed pattern of deficits reflects an interaction between GRM2/3 genotype and the arousalinducing properties of the experimental paradigms. This fractionation is not only unique, to our knowledge, but may be of importance with regard to the interface between cognition and motivation, and to their involvement in schizophrenia and other disorders.

\section{SUBJECTS AND METHODS}

\section{Subjects}

Age-matched, male, wild-type, and GRM $2 / 3^{-1-}$ mice were obtained from GlaxoSmithKline, Harlow, UK (for details, see Supplementary Material). Behavioral experiments were conducted under the auspices of UK Home Office Project and Personal licenses held by the investigators, and the study was approved by the local ethics committee. Four cohorts of mice were used. For full details of subjects and testing order see Supplementary Material.

\section{Overview of Experimental Design for Assessment of Hippocampus-Dependent Spatial Memory}

A series of experiments was conducted, in which results from one set of experiments were used to generate hypotheses, which were then tested in subsequent experiments. For clarity, this iterative, chronological sequence is summarized here before individual experiments are described in detail. Our initial experiments revealed that GRM2/3 $3^{-I-}$ mice were impaired on appetitively motivated tasks measuring either SRM and/or SWM (experiments 1 to 3; Y-maze, T-maze, and radial-arm maze). GRM2/3 ${ }^{-l-}$ mice were, however, unimpaired on the aversively motivated Morris water maze SRM task (experiment 4). Further experiments were thus conducted to explore this dissociation.

The open field water maze differs from the 'dry land' mazes not only in terms of its aversive character, but also in terms of other procedural aspects. To reconcile these differences, we directly compared experimentally naïve GRM $2 / 3^{-l-}$ and wild-type mice with appetitive and aversive versions of the Y-maze SRM task using a fully counterbalanced design (experiment 5). These data confirmed that the observed dissociations were not merely consequences of differences in the mazes used, the spatial cues available, or the order of testing. We then performed further experiments to explore further the nature of the deficit in the GRM2 $/ 3^{-7-}$ mice. Experiment 6 examined whether the deficit extended to appetitively motivated, hippocampusindependent, behavioral paradigms by assessing performance on a non-spatial, visual discrimination learning task. Experiment 7 examined spatial memory performance in a spontaneous, exploratory task with neither a food reward nor an escape contingency. Finally, amphetamine challenge experiments were used to explore the effects of pharmacologically manipulating arousal levels on locomotor activity and cognition (experiments 8 and 9). Detailed 
methods, in addition to those presented below, can be found in the Supplementary Material.

\section{Experiment 1: Appetitively Motivated SRM on the Elevated Y-Maze}

Each mouse was assigned a goal arm, defined by its position relative to extramaze spatial cues, which was baited with sweetened condensed milk on all trials. On each trial, the mouse was placed at the end of one of the two non-baited arms (the 'start arm'), and allowed to choose one of the remaining arms. If it chose the goal arm, it was allowed to consume the milk reward before being returned to the home cage. Mice that chose incorrectly were returned to the home cage immediately. Previous work in this laboratory has demonstrated that this task is hippocampus dependent (Deacon et al, 2002). Mice received 10 trials per day for 9 days, with an inter-trial interval (ITI) of approximately $5 \mathrm{~min}$.

\section{Experiment 2: Appetitively Motivated SWM on the Elevated T-Maze}

Each trial consisted of a sample run followed by a choice run. On the sample run, mice were forced either left or right by the presence of a wooden block, closing off one of the goal arms. At the end of the goal arm, the mouse collected a reward of sweetened condensed milk. The block was then removed and the mouse placed back in the start arm, facing the experimenter, for the choice run. The mouse could now select either goal arm but was rewarded only for choosing the arm that had not been visited on the sample run, that is, for alternating (non-matching to place). The interval between the sample and choice runs was approximately $5 \mathrm{~s}$. Mice received five trials per day, with an ITI of approximately $10 \mathrm{~min}$. SWM performance on the T-maze is also dependent on the hippocampus (Deacon et al, 2002).

\section{Experiment 3: SRM and SWM in the Six-Arm Radial Maze}

A two-stage, within-subjects and within-task design was used (Schmitt et al, 2003).

SRM acquisition. In the initial acquisition phase, three of the six arms were baited with sweetened condensed milk. At the start of each trial, the mouse was placed on the central platform and given a free choice of arms. After visiting the food well in the chosen arm, the mouse would return to the central platform. The door to the visited arm was then closed and remained so for all subsequent choices on that trial, preventing the mouse from re-entering that arm. After $10 \mathrm{~s}$, all other doors were opened and the mouse allowed a second choice. This was repeated, with five doors open for the second choice, four for the third, and so on, until the mouse had visited all three baited arms. Each entry into an un-baited arm was scored as a SRM error. SRM acquisition on the radial maze is prevented by cytotoxic hippocampal lesions (Schmitt et al, 2003).

Simultaneous assessment of SRM and SWM. When all mice had successfully acquired the SRM task, the SWM component was introduced. Entries into previously visited arms were now no longer prevented but the food rewards were not replaced within a trial. Three types of error were scored (Jarrard, 1993), including SRM errors in which the mouse visited a never-baited arm, and SWM errors in which the mouse visited a baited arm that had already been visited on that trial. If second and subsequent visits to a neverbaited arm occurred, these were scored separately as SRMrepeat errors.

\section{Experiment 4: Aversively Motivated SRM in the Open Field Morris Water Maze}

To escape from the water, mice had to locate a platform, hidden approximately $1 \mathrm{~cm}$ below the surface, which for a given mouse remained in the same position on all trials. Each mouse was given four trials per day for 9 days. After trials 24 and 36, transfer (probe) tests were conducted. The platform was removed from the pool and the mouse allowed to swim freely for $60 \mathrm{~s}$. The percentage of time spent in each quadrant was recorded, together with the number of times the mouse swam across the former location of the platform. We have previously shown in this same laboratory, with the same spatial cues, that acquisition of this fixed location, hidden platform water maze task is prevented by cytotoxic hippocampal lesions (Deacon et al, 2002).

\section{Experiment 5: Comparison of Appetitively and Aversively Motivated SRM on the Y-Maze}

The aim of this experiment was to compare performance of wild-type and GRM2/3 $3^{-1-}$ mice with appetitively and aversively motivated versions of the Y-maze SRM task, with the order of testing and the experimental rooms in which the tests were performed (and therefore the spatial cues available), fully counterbalanced in order to control for practice effects or differences in the salience of the available spatial cues. Thus, $50 \%$ of wild-type and $50 \%$ of GRM $2 / 3^{-l-}$ mice first performed the appetitive Y-maze SRM task described in experiment 1 (same apparatus and protocol), in room A. These animals then performed an aversively motivated Y-maze SRM task (see below), in room B. Conversely, the remaining $50 \%$ began with the aversively motivated Y-maze task in room A, followed by the appetitively motivated Y-maze task in room B.

In the deep-water escape (aversive) Y-maze, mice could escape from the water by climbing onto a platform hidden approximately $1.5 \mathrm{~cm}$ below the water surface. Mice received five trials per day for 6 days. On each trial, the mouse was allowed $90 \mathrm{~s}$ to find the platform; any that failed to do so were guided there by the experimenter. On day 7 , a transfer test was performed, analogous to that used in the water maze. The platform was removed from the maze and the mouse allowed to swim freely for $30 \mathrm{~s}$. Time spent searching in each arm was recorded. Previous work within this laboratory has confirmed that the 'swimming Y-maze' task, like the appetitive Y-maze, is hippocampus dependent.

\section{Experiment 6: Appetitively Motivated Visual Discrimination}

One possible explanation for this pattern of results is that GRM2 $/ 3^{-I-}$ mice have reduced appetitive motivation for the 
milk reward. If this were the case, then one would expect the mice to be impaired on other appetitively motivated tasks.

Visual discrimination learning for a food reward was examined using a T-maze with a light gray start arm, plus two removable goal arms. Successful performance involves learning an association between a visual pattern and reward, but does not require the hippocampus (Morris et al, 1986; Murray and Ridley, 1999). The walls and floor of one of the goal arms were painted with black and white stripes, while those of the other goal arm were plain dark gray. Each mouse was assigned a particular goal arm ('black/white stripes' or 'gray'), which was baited with sweetened condensed milk on all trials. On $50 \%$ of trials, the rewarded goal arm was positioned to the right of the start arm, and on the remaining $50 \%$, to the left (according to a pseudorandom sequence). On each trial, the mouse was placed at the end of the start arm and allowed to choose one of the goal arms. If the mouse chose the correct arm, it was allowed to consume the milk reward before being returned to the home cage. Mice that chose incorrectly were returned to the home cage immediately. Mice received 10 trials per day for 5 days.

\section{Experiment 7: Spontaneous Spatial Novelty Preference Task}

GRM2 $/ 3^{-l-}$ and wild-type mice were also compared with a spontaneous, spatial novelty preference task in which behavior is driven, not by an overt unconditioned stimulus (eg, a food reward), but instead relies on animals' natural exploratory drive. This task, therefore, provides a nonaversive experimental context but performance does not rely on the motivating or rewarding effects of food.

The apparatus used was identical to the swimming Y-maze, but without the water. Each mouse was assigned two arms (the 'start arm' and the 'other arm') to which they were exposed during the first phase of the task (the 'exposure phase'). During this 5-min 'exposure' phase, the entrance to the third, 'novel', arm was closed off by the presence of a large Perspex block. At the end of $5 \mathrm{~min}$, the mouse was removed from the maze and returned to the home cage for $1 \mathrm{~min}$. The mouse was then returned to the start arm for the test phase. This consisted of 2 min free exploration during which the mouse could now enter all three arms. The amount of time that the mouse spent in each arm, and the number of entries into each arm, were recorded, during both the exposure and test phases. For the test phase, a discrimination ratio ((novel arm/(novel + other arm)) was calculated. Previous work has demonstrated that wild-type mice display a marked preference for the novel arm during the test phase, which is abolished by cytotoxic hippocampal lesions (Sanderson et al, 2007).

\section{Experiment 8: Spontaneous and Amphetamine-Induced Locomotor Activity}

Spontaneous locomotor activity was first measured in transparent plastic photocell activity cages over $2 \mathrm{~h}$. The number of beam breaks made by each mouse was recorded in 24 bins of $5 \mathrm{~min}$. A separate cohort of mice were then tested in a threshold activity monitoring system for locomotor activity over a 70 -h period (1-h bins).
A further separate cohort of drug-naïve mice, with no previous experience of the photocell activity boxes, was used for the amphetamine challenge experiments. Mice were habituated to the activity boxes for $20 \mathrm{~min}$ before receiving an i.p. injection of either saline or $2.5 \mathrm{mg} / \mathrm{kg}$ amphetamine (injection volume $10 \mathrm{ml} / \mathrm{kg}$ body weight). Activity levels (number of beam breaks) were then measured for $2 \mathrm{~h}$.

Higher doses of amphetamine are known to induce stereotypy, which reduces locomotor activity. An additional cohort of drug-naïve mice was habituated to the activity boxes for $20 \mathrm{~min}$ before receiving an i.p. injection of either saline or $10 \mathrm{mg} / \mathrm{kg}$ amphetamine $(10 \mathrm{ml} / \mathrm{kg}$ body weight). Mice were returned immediately to the activity boxes and their activity levels measured for $7 \mathrm{~h}$. Every $10 \mathrm{~min}$ throughout the first $4 \mathrm{~h}$, stereotypy was scored for each animal, using an established rating scale (Creese and Iversen, 1974).

\section{Experiment 9: Effect of Injection Stress and a Low Dose} of Amphetamine on Appetitively Motivated T-Maze SWM

To assess the effect of a low dose of amphetamine $(0.5 \mathrm{mg} / \mathrm{kg})$ on cognitive performance, we trained drug-naïve wildtype $(n=12)$ and GRM $2 / 3^{-I-}(n=11)$ mice on a T-maze rewarded alternation SWM task (as in experiment 2). When the performance of both groups was stable, animals received a session of 10 trials with no injections. The following day, they were injected with either $0.5 \mathrm{mg} / \mathrm{kg}$ amphetamine or saline (i.p; $10 \mathrm{ml} / \mathrm{kg}$ body weight), according to a counterbalanced, within-subjects design. Each animal received a block of 10 trials on the T-maze SWM task 20 min after each injection, with drug and vehicle injections separated by $24 \mathrm{~h}$. Finally, $24 \mathrm{~h}$ later, all animals received a final block of 10 trials with no injection.

\section{RESULTS}

\section{Experiment 1: Impaired Appetitive SRM on the Elevated} Y-Maze

All GRM2/3 $3^{-1-}$ mice $(n=14)$ and wild-type $(n=18)$ mice were able to learn the spatial location of the sweetened condensed milk reward on the Y-maze, a task that has previously been shown to be sensitive to hippocampal lesions (Deacon et al, 2002). However, the rate of acquisition of this appetitive SRM task was slower in GRM2 $/ 3^{-1-}$ mice (Figure 1a). Two-way RM-ANOVA revealed an effect of group $\left(\mathrm{F}_{(1,30)}=8.88 ; p=0.006\right)$ and block $\left(\mathrm{F}_{(8,240)}=82.98 ; p<0.001\right)$, as well as a group $\times$ block interaction $\left(\mathrm{F}_{(8,240)}=5.06 ; p<0.001\right)$. Duncan's multiple pairwise comparisons revealed that GRM $2 / 3^{-1-}$ mice were impaired in blocks 3-6 inclusive (all $p<0.05$ ). Post-choice reinforcement in block 9 confirmed that mice were not locating the milk by virtue of its odor.

\section{Experiment 2: Impaired SWM on the Elevated T-Maze}

Wild-type mice $(n=18)$ successfully performed this task, alternating their spatial responses in order to obtain a condensed milk reward. Although GRM2/3 ${ }^{-1-}$ mice $(n=14)$ 

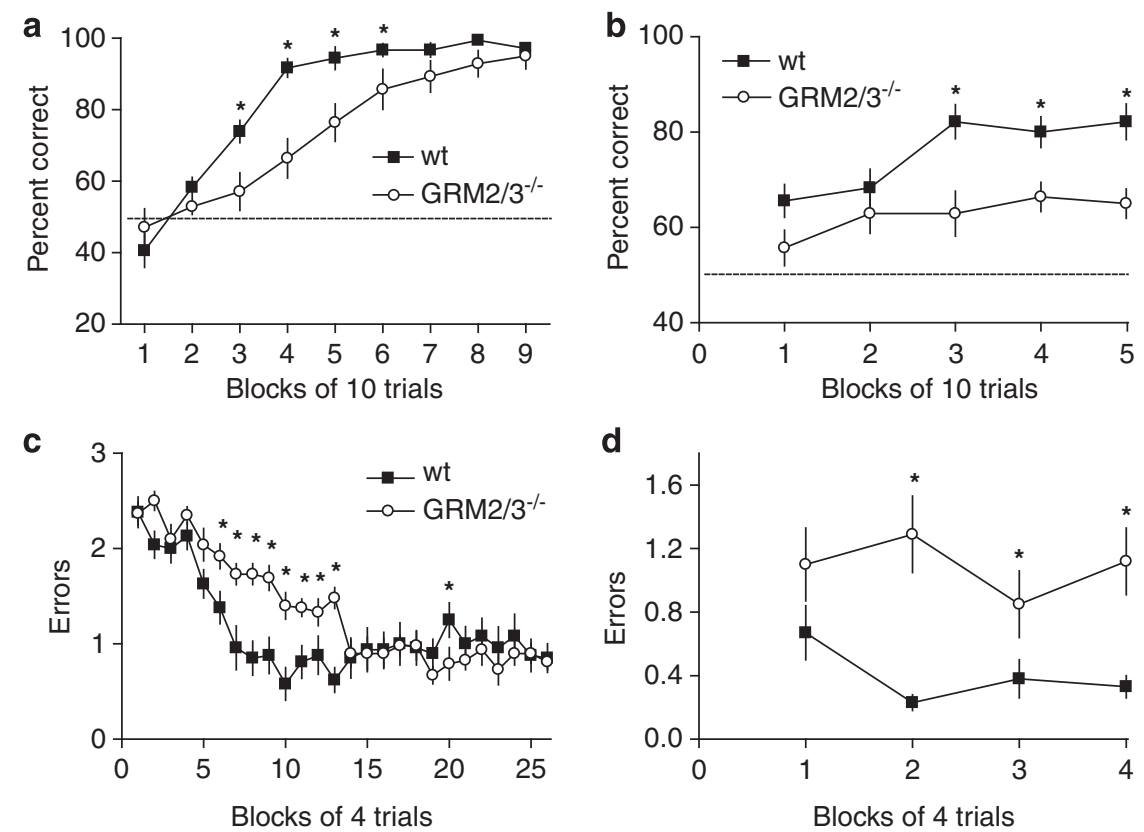

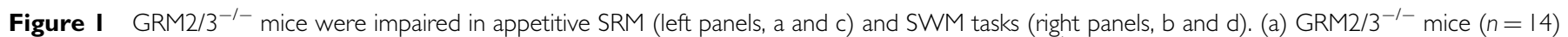
displayed slower acquisition of a Y-maze SRM task than wild-type ( wt; $n=18)$ mice and (b) GRM2/3 ${ }^{-1-}$ mice $(n=14)$ were persistently impaired in an appetitive T-maze rewarded alternation SWM task compared with wild-types ( $\mathrm{wt} ; n=18)$. Data shown are percent correct responses (mean \pm SEM) for each block of 10 trials. Chance performance is indicated by the dashed line. (c) GRM2/3 $3^{-1-}$ mice $(n=13)$ displayed slower acquisition of the SRM component of an appetitive six-arm radial maze task than wt $(n=13)$ and (d) GRM2/3 ${ }^{-1-}$ mice subsequently made significantly more SWM errors than wt. Data shown are mean errors $( \pm$ SEM) per trial in each block of four trials. Asterisks indicate statistical significance at $p<0.05$.

did improve marginally over the course of training, they remained significantly impaired relative to their wildtype counterparts throughout (Figure 1b; effect of group: $\mathrm{F}_{(1,30)}=16.43 ; p<0.001$; effect of block: $\mathrm{F}_{(4,120)}=5.33$; $p<0.001$; no group $\times$ block interaction: $\mathrm{F}_{(4,120)}=1.54$; $p=0.196)$.

In a separate cohort of wild-type $(n=17)$ and GRM $2 / 3^{-1-}$ mice $(n=22)$, we replicated this experiment again showing that GRM2/3 $3^{-I-}$ mice $(71.4 \pm 1.4 \%$ correct) were impaired relative to wild-type controls $(77.6 \pm 2.0 \%$ correct; $\left.\mathrm{F}_{(1,37)}=6.63 ; p<0.05\right)$. In addition, we recorded the latency of the mice to run (i) from the beginning of the start arm to the food well on the sample trial, and (ii) from the beginning of the start arm until making a choice into one of the goal arms on the choice trial. Importantly, the deficit in the GRM $2 / 3^{-1-}$ mice was not due to the fact that these animals simply ran more slowly and thus experienced an increase in the delay between the sample trial and choosing on the choice trial, increasing the mnemonic demands of the task. In fact, the GRM $2 / 3^{-1-}$ mice displayed shorter latencies than their wild-type controls on both the sample (median and inter-quartile range(s); wildtype $=7.1 \quad(4.3-64.0), \quad$ GRM $2 / 3^{-I-}=3.4 \quad(2.8-7.2$; MannWhitney $U$-test, $p<0.05)$ and choice runs (median and inter-quartile range(s); wild-type $=8.5(3.3-40.6)$, GRM2/ $3^{-l-}=2.5(2.0-7.2$; Mann-Whitney $U$-test, $p<0.005)$ during performance on this task.

\section{Experiment 3: Impaired SRM and SWM on the Six-Arm Radial Maze}

To confirm the results of experiments 1 and 2, GRM2/3 ${ }^{-1-}$ and wild-type mice were compared with a six-arm radial maze task, which permits simultaneous assessment of SRM and SWM. In the first stage, animals had to learn to discriminate between three baited and three non-baited arms (SRM). GRM $2 / 3^{-1-}$ mice displayed slower acquisition of this SRM component than wild-type animals (Figure 1c). Two-way RM-ANOVA revealed an effect of block $\left(\mathrm{F}_{(25,600)}=25.91 ; p<0.001\right)$, as well as a group $\times$ block interaction reflecting the differing rates of acquisition $\left(\mathrm{F}_{(25,600)}=4.25 ; p<0.001\right)$. The main effect of group failed to reach significance $\left(\mathrm{F}_{(1,24)}=3.08 ; p=0.092\right)$, but Duncan's multiple pairwise comparisons confirmed that the GRM2/ $3^{-1-}$ mice were significantly impaired in blocks 6 to 13 inclusive (all $p<0.05$ ). The performance of the two groups was well matched from block 14 onward (all $p>0.05$, with the exception of block 20 in which GRM $2 / 3^{-1-}$ mice actually made fewer errors than wild-type animals, $p<0.05$ ). These additional blocks of trials were conducted to ensure that both groups of mice were well matched for SRM performance, and thoroughly familiar with the location of the three rewarded arms, before the introduction of the SWM component.

In the second stage of this task, entries into already visited arms were now no longer prevented. Comparison of SWM error rates revealed that, as with T-maze rewarded alternation (experiment 2), GRM $2 / 3^{-1-}$ mice were again less able to remember which arms they had already visited on a given trial (Figure 1d; main effect of group: $\mathrm{F}_{(1,24)}=38.91$; $p<0.001$; no effect of block: $\mathrm{F}_{(3,72)}=0.74 ; p=0.531$; no group $\times$ block interaction: $\left.\mathrm{F}_{(3,72)}=1.34 ; p=0.268\right)$. By this stage of training, both groups of mice were maintaining similarly low levels of SRM errors (no effect of group: $\mathrm{F}_{(1,24)}=2.55 ; p=0.124$; no effect of block: $\mathrm{F}_{(3,72)}=1.02$; $p=0.387 ;$ no group $\times$ block interaction: $\mathrm{F}_{(3,72)}=1.53$; 
$p=0.214)$. SRM-repeat errors were therefore very infrequent in both groups of mice (average $<0.2$ per trial) (no effect of group: $\mathrm{F}<1 ; p>0.20$; or block: $\mathrm{F}_{(3,72)}=1.80$; $p=0.155$; and no interaction: $\mathrm{F}<1 ; p>0.20$ ) (data not shown).

Overall therefore, GRM $2 / 3^{-l-}$ mice displayed slower but ultimately successful acquisition of the initial SRM phase, consistent with their slower acquisition but eventual success on the SRM Y-maze task (experiment 1 ). GRM $2 / 3^{-1-}$ mice also exhibited a persistent SWM impairment, consistent with their impaired performance on $\mathrm{T}$-maze rewarded alternation (experiment 2).

\section{Experiment 4: Unimpaired Aversive SRM in the Open Field Morris Water Maze}

The performance of GRM $2 / 3^{-1-}$ mice was examined in the standard, fixed location, hidden platform Morris water maze task. In contrast to the appetitive spatial memory tasks, GRM2 $/ 3^{-I-}$ mice were completely unimpaired $(n=18 \mathrm{wt}$; $n=13$ GRM $2 / 3^{-1-}$; Figure 2$)$. As GRM $2 / 3^{-1-}$ mice swam more slowly than wild-types $(0.19 \pm 0.004 \mathrm{~cm} / \mathrm{s} \quad v s$ $\left.0.21 \pm 0.003 \mathrm{~cm} / \mathrm{s} ; t_{(29)}=4.62 ; p<0.001\right)$, distance traveled to reach the platform (path length) was taken as the performance measure during training. Two-way RM-ANOVA revealed an effect of day $\left(\mathrm{F}_{(8,232)}=59.22 ; p<0.001\right)$, but no effect of group, nor group $\times$ day interaction (both $\mathrm{F}<1 ; p>0.20$ ).

Probe tests were conducted on days 7 and 11 (24h after training trials 24 and 36, respectively), in which the platform was removed from the pool and the animal allowed to swim freely for $60 \mathrm{~s}$. In both probe tests, wildtype and GRM $2 / 3^{-I-}$ mice concentrated their search in the quadrant that had previously held the platform (Figures $2 \mathrm{~b}$ and c). In the analysis of the distribution of time spent searching the four quadrants, the numerator term in the degrees of freedom was reduced by one to control for the fact that the quadrant dwell times were not independent. This analysis confirmed an effect of quadrant in both probe tests (day 7, $\mathrm{F}_{(2,87)}=31.16 ; p<0.05$; day $11, \mathrm{~F}_{(2,87)}=49.81$; $p<0.05)$, but no group by quadrant interaction on either (day $7, \mathrm{~F}<1 ; p>0.20$; day $11, \mathrm{~F}_{(2,87)}=1.91 ; p=0.13$ ). A between-subjects $t$-test comparing the proportion of time spent searching in the training quadrant confirmed that both groups had learned the location of the platform to the same extent (day $7, t_{(29)}=1.01 ; p=0.32$; day 11 , $\left.t_{(29)}=1.39 ; p=0.18\right)$.

The number of 'annulus crossings' made by the two groups (ie, the number of times the mouse swam across the former location of the platform, along with the number of crossings of the equivalent positions in the other quadrants), were also compared. The results revealed equivalent performance in wild-type and GRM $2 / 3^{-1-}$ mice in both probe tests (day 7 , effect of quadrant: $\mathrm{F}_{(3,87)}=21.34$; $p<0.001$, but no effect of group: $\mathrm{F}_{(1,29)}=1.73 ; p=0.198$, and no group $\times$ quadrant interaction: $\mathrm{F}<1 ; p>0.20$; day 11 , effect of quadrant: $F_{(3,87)}=28.06 ; p<0.001$, but no effect of group: $\mathrm{F}<1 ; p>0.20$, and no interaction: $\mathrm{F}_{(3,87)}=1.89$; $p=0.137)$. This was confirmed by comparison of the number of annulus crossings in the training quadrant only (day $7, U=210.5 ; p=0.602$; day $11, t_{(29)}=1.14 ; p=0.263$; see Supplementary Material, Figure S1).

Finally, the data were used to calculate accuracy scores, based on a comparison of the number of platform crossings in each of the four quadrants (accuracy score=TRA $(($ Opp $+\operatorname{AdjL}+\operatorname{AdjR}) / 3))$, where TRA, Opp, AdjL, and AdjR are the number of platform crossings in the training, opposite, adjacent left, and adjacent right quadrants, respectively. Again, there were no group differences in either of the probe tests (day 7, $\mathrm{F}<1 ; p>0.20$; day 11, $\left.\mathrm{F}_{(1,29)}=2.40 ; p=0.132\right)$.

\section{Experiment 5: Impaired Appetitively Motivated SRM but} Spared Aversively Motivated SRM in the Y-Maze

Experimentally naïve GRM $2 / 3^{-l-}(n=25)$ and wild-type $(n=25)$ mice were compared with two different versions of the Y-maze SRM task: one appetitively motivated (as in experiment 1) and the other, an aversively motivated 'swimming Y-maze (water escape)' task. All mice were motivated to escape from the water and readily learned the aversive task. GRM $2 / 3^{-I-}$ mice were unimpaired in the aversive version of the Y-maze SRM task (no effect of group: $\mathrm{F}<1 ; p>0.20$; effect of block: $\mathrm{F}_{(5,240)}=25.61 ; p<0.001$; no group $\times$ block interaction: $\mathrm{F}<1 ; p>0.20$ ) (Figure $3 \mathrm{a}$ ). In a probe test conducted on day 7 , in which the platform was removed from the maze and the animals allowed to swim freely for $30 \mathrm{~s}$, both groups of mice concentrated their search in the arm that had previously held the platform:
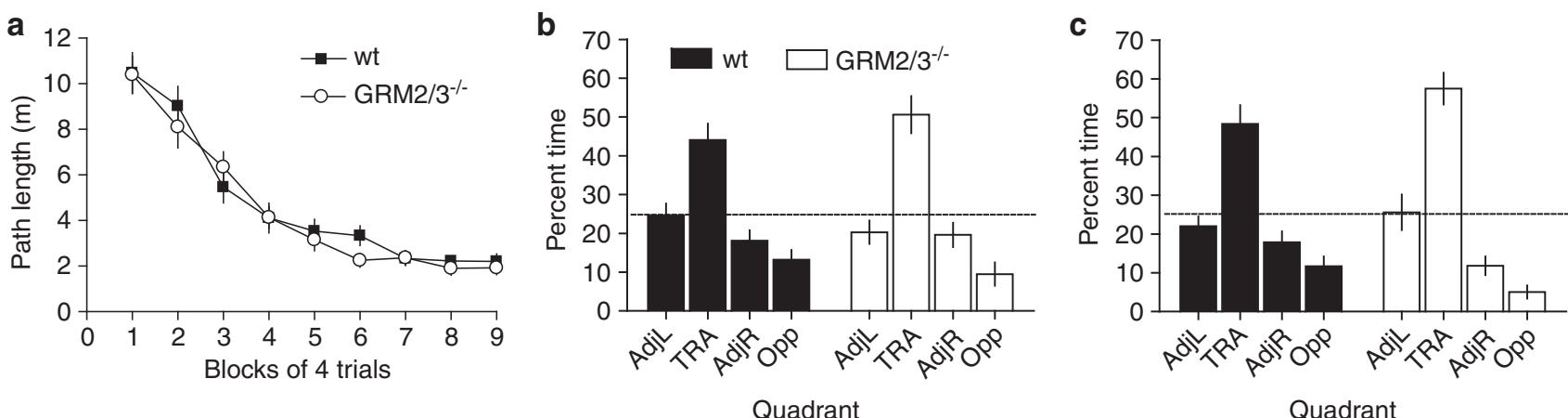

Figure 2 GRM2 $/ 3^{-1-}$ mice $(n=13)$ did not differ from wild-type mice $(w t ; n=18)$ in the water maze SRM task. (a) Path length for each day of testing during acquisition. (b) Percentage time spent in the adjacent left (AdjL), training (TRA), adjacent right (AdjR), and opposite (Opp) quadrants in probe test I (day 7). (c) Percentage time spent in each quadrant in probe test 2 (day II). Chance performance is indicated by the dashed line. Values are mean \pm SEM. 
wild-types spent $55.2 \pm 2.0 \%$ of total search time in the correct arm, $t_{(24)}=2.53 ; p=0.018$ compared with chance; GRM $2 / 3^{-I-}$ mice spent $61.8 \pm 2.6 \%$ of total search time in the correct arm, $t_{(24)}=4.49 ; p<0.001$ compared with chance). In fact, there was a trend for GRM $2 / 3^{-1-}$ mice to spend a greater proportion of time in the correct arm than wild-type animals $\left(t_{(48)}=2.00 ; p=0.051\right)$ (Figure $3 \mathrm{a}$; inset).

In contrast, GRM2/3 ${ }^{-1-}$ mice once again displayed slower acquisition of the appetitive Y-maze SRM task (effect of group: $\mathrm{F}_{(1,48)}=19.01 ; p<0.001$; effect of block: $\mathrm{F}_{(8,384)}=173.15$; $p<0.001$; group $\times$ block interaction: $\mathrm{F}_{(8,384)}=7.91 ; p<0.001$; $n=25$ in each group; Figure $3 \mathrm{~b}$ ). These results are consistent with a dissociation between appetitive and aversive spatial memory task performance in GRM $2 / 3^{-1-}$ mice.

\section{Experiment 6: Unimpaired Appetitive Visual Discrimination Learning}

To examine whether the GRM $2 / 3^{-l-}$ deficit extended to an appetitively motivated, non-spatial task, GRM $2 / 3^{-1-}$ $(n=14)$ and wild-type $(n=18)$ mice were compared with a simple 'gray' $v s$ 'black/white stripes' visual discrimination task in the T-maze. A two-way RM-ANOVA revealed an effect of block $\left(\mathrm{F}_{(4,120)}=42.22 ; p<0.001\right)$, but no effect of group and no group $\times$ block interaction (both $\mathrm{F}<1$; $p>0.20$ ) (Figure 4a). Post-choice reinforcement in block 5 confirmed that mice were not locating the milk by virtue of its odor. This demonstrates, therefore, that GRM $2 / 3^{-1-}$ mice do not display a general deficit on all appetitively motivated maze tasks.

\section{Experiment 7: Impaired Spontaneous Spatial Novelty Preference}

This test of spatial memory is neither appetitively nor aversively motivated, but relies on animals' natural exploratory drive. If the deficit in GRM $2 / 3^{-1-}$ mice simply reflects a reduced appetitive motivation for food rewards, then one would expect normal memory performance on this spatial novelty preference task. During the initial exposure phase, GRM2/3 ${ }^{-1-}(n=13)$ and wild-type $(n=18)$ mice spent a similar amount of time exploring the two available arms (the 'start' and 'other' arms $)\left(\mathrm{F}_{(1,29)}=1.632 ; p=0.212\right.$; no group $\times$ arm interaction: $\mathrm{F}<1 ; p>0.20)$. There was a tendency for GRM $2 / 3^{-1-}$ mice to make fewer arm entries in total, however $\left(t_{(29)}=2.05 ; p=0.05\right)$, suggesting that they were less active. GRM $2 / 3^{-l-}$ mice made fewer entries into the 'start' arm than wild-type animals $\left(t_{(29)}=2.43 ; p=0.022\right)$,
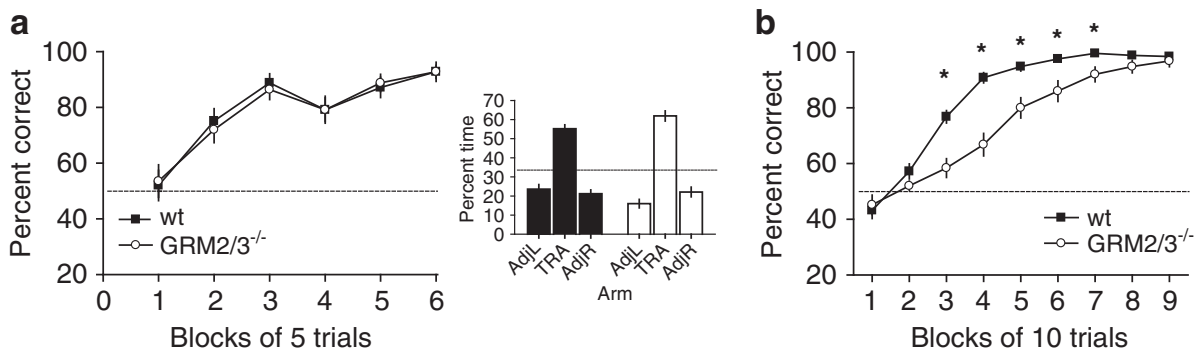

Figure $3 \mathrm{GRM} 2 / 3^{-1-}$ mice show a dissociation between performance on appetitive and aversive spatial memory tasks. (a) GRM2/3 ${ }^{-1-}$ mice $(n=25)$ learned the swimming SRM Y-maze task at the same rate as wild-type mice ( $w t ; n=25)$. Data shown are mean percent correct responses $( \pm$ SEM) for each block of 5 trials. Inset: in a probe test on day $7, \mathrm{GRM} 2 / 3^{-1-}$ mice spent an equal or greater $(p=0.05 \mathrm{I})$ proportion of their time searching in the arm that had previously held the platform, relative to wild-type mice. (b) GRM2/3 ${ }^{-1-}$ mice $(n=25)$ displayed slower acquisition of the appetitive SRM Y-maze task than wild-type controls $(n=25)$. Data shown are mean percent correct responses $( \pm$ SEM) for each block of 10 trials. Order of testing and the rooms in which the tests were performed were fully counterbalanced. Chance performance is indicated by the dashed line. ${ }^{*} p<0.05$.
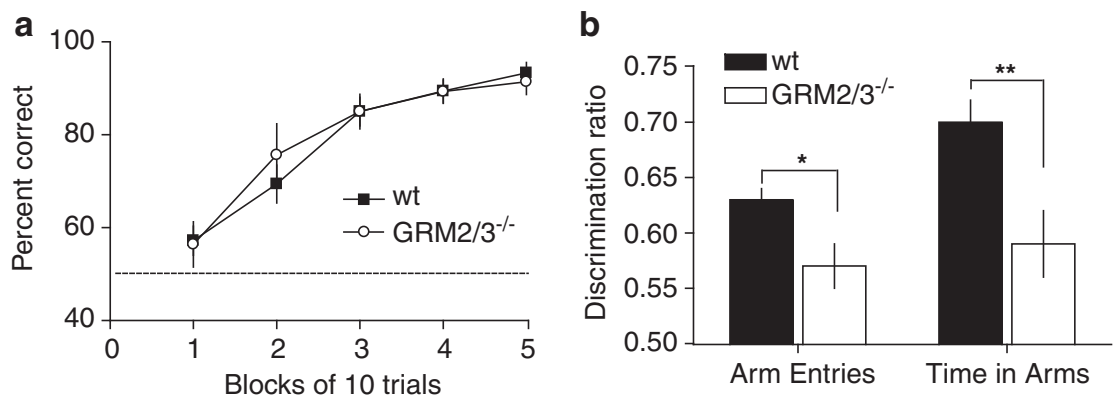

Figure 4 Cognitive deficits in GRM2/3 ${ }^{-1-}$ mice cannot be explained simply by reduced appetitive motivation for the milk reward. (a) GRM2/3 ${ }^{-1-}$ mice $(n=14)$ did not differ from wild-type mice $(w t ; n=18)$ in acquisition of an appetitively motivated, non-spatial gray vs black-white stripes visual discrimination task (experiment 6 ). Data shown are mean percent correct responses ( \pm SEM) for each block of 10 trials. Chance performance is indicated by the dashed line. (b) GRM2/3 ${ }^{-1}$ mice $(n=13)$ show a reduced spatial novelty preference compared with wild-type animals $(n=18$; experiment 7$)$. Data shown are mean discrimination ratios ((novel arm/(novel + other arm)) ( \pm SEM) calculated for the number of arm entries (left) and the time spent in the arms (right) during the test phase. The discrimination ratio was significantly lower for GRM2/3 ${ }^{-1-}$ mice on both measures. A discrimination ratio of 0.5 reflects chance performance. $\left(* p<0.05\right.$ and $\left.{ }^{*} * p=0.005\right)$. 
but importantly the number of entries into the 'other' arm did not differ between the groups $\left(t_{(29)}=1.57 ; p=0.128\right)$.

In the subsequent test phase, both groups displayed a preference for the previously unvisited, 'novel' arm over the now familiar, 'other' arm (Figure 4b). This preference was stronger in the wild-type mice. Statistical analysis of the discrimination ratio (novel arm/(novel + other arm)) confirmed that wild-type mice showed a preference for the 'novel' arm that was above chance (chance = discrimination ratio of 0.50$)$, both in terms of arm entries $\left(t_{(17)}=9.54\right.$; $p<0.001)$ and time spent in arms $\left(t_{(17)}=9.63 ; p<0.001\right)$. The discrimination ratio for the $\mathrm{GRM} 2 / 3^{-1-}$ mice was also above chance, again in terms both of arm entries $\left(t_{(12)}=3.59 ; p=0.004\right)$ and time spent in arms $\left(t_{(12)}=2.94\right.$; $p=0.012)$. Importantly, the 'novel' arm preference was stronger in the wild-type mice than in GRM $2 / 3^{-1-}$ mice: wild-type mice made a higher proportion of 'novel' arm entries $\left(t_{(29)}=2.64 ; p=0.013\right)$ and spent a significantly greater proportion of time in the 'novel' arm $\left(t_{(29)}=3.05\right.$; $p=0.005)$ than $\mathrm{GRM} 2 / 3^{-1-}$ mice. Taken in conjunction with the result of experiment 6 , this shows that the GRM $2 / 3^{-1-}$ cognitive deficit cannot be attributed to a reduction in appetitive motivation.

\section{Experiment 8: GRM2/3 Knockout Mice Display Reduced Spontaneous and Amphetamine-Induced Locomotor Activity}

GRM $2 / 3^{-I-}$ mice were hypoactive relative to wild-type controls. A photocell beam breaks test, conducted in a novel cage environment and lasting for $2 \mathrm{~h}(24 \times 5$-min blocks), revealed less spontaneous locomotor activity in GRM2/3 $3^{-1-}$ mice (effect of group: $\mathrm{F}_{(1,30)}=8.20 ; p=0.008$; effect of block: $\mathrm{F}_{(23,690)}=32.66 ; p<0.001$; no group $\times$ time interaction: $\mathrm{F}_{(23,690)}=1.35 ; p=0.127 ; 18$ wild-types $v s 14$ GRM2 $/ 3^{-1-}$ mice; Figure $5 \mathrm{a}$ ).

In a separate cohort of wild-type $(n=17)$ and GRM2/3 ${ }^{-1-}$ mice $(n=22)$, locomotor activity was tested over a 70 -h period $(70 \times 1$-h blocks $)$ in a threshold activity monitoring system (see Supplementary Material; Supplementary Figure 2). ANOVA revealed an overall main effect of group $\left(\mathrm{F}_{(1,37)}=5.94 ; p<0.05\right)$, which reflected the fact that wildtype mice were more active overall than the knockouts. There was also a main effect of block $\left(\mathrm{F}_{(69,2553)}=46.1\right.$; $p<0.0001$ ), which reflected the changes in diurnal activity over the course of the experiment, and a significant group by block interaction $\left(\mathrm{F}_{(69,2553)}=2.09 ; p<0.0001\right)$. Analysis of simple main effects revealed that the activity levels of the groups differed significantly between 1 and $4 \mathrm{~h}$ after first being placed in the novel activity cages, and then again consistently during the middle of the dark phase on each of the 3 days of continual testing in these cages (for full details, see Supplementary Material and Supplementary Figure S2). On 13 out of 14 time blocks in which the two groups differed, the wild-type mice were more active than the GRM $2 / 3^{-I-}$ mice.

A moderate dose of amphetamine $(2.5 \mathrm{mg} / \mathrm{kg})$ increased activity levels in both GRM $2 / 3^{-1-}(n=10)$ and wild-type $(n=12)$ mice by approximately $100 \%$. GRM $2 / 3^{-1-}$ mice therefore remained hypoactive relative to wild-type controls after this amphetamine treatment (effect of group: $\mathrm{F}_{(1,20)}=4.85 ; \quad p=0.039$; effect of drug: $\mathrm{F}_{(1,20)}=15.94$; $p<0.001$; no group $\times$ drug interaction: $\mathrm{F}<1 ; p>0.20$ ) (Figures $5 b(\mathrm{i})$ and (ii)).

Following injection of $10 \mathrm{mg} / \mathrm{kg}$ amphetamine, wild-type mice $(n=5)$ displayed an initial burst of activity (as did wild-type saline-injected controls; $n=6$; Figure $5 c$ ). Activity levels then fell sharply, well below the activity levels in the wild-type saline controls, concomitant with an increase in observed stereotypical behaviors (Supplementary Material, Supplementary Figure S3). Approximately 2.5-h postinjection, activity levels in the wild-type amphetamine group began to rise again as stereotypy decreased. For the next 3 to $4 \mathrm{~h}$, activity levels in the wild-type amphetamine mice were considerably greater than in the wild-type saline animals, before returning back to wild-type saline levels between 6- and 7-h post-injection. The initial burst of activity was notably reduced in the GRM $2 / 3^{-1-}$ mice (amphetamine: $n=6$; saline: $n=6$ ) compared with wildtypes. Similar to wild-type mice, however, activity levels in amphetamine-treated GRM $2 / 3^{-l-}$ mice declined sharply as stereotypical behaviors increased, remaining low until approximately 2.5 -h post-injection, when they then began to increase again as stereotypies reduced, paralleling the change in the wild-type mice. The increase in locomotor activity observed between 2.5- and 6.5-h post-injection of amphetamine was substantially less in the GRM $2 / 3^{-l-}$ mice compared with wild-types and, importantly, at no point did locomotor activity in GRM $2 / 3^{-1-}$ mice exceed that of wildtype mice. Statistically, these observations reflected overall effects of drug $\left(\mathrm{F}_{(1,19)}=14.07 ; p=0.0014\right)$, genotype $\left(\mathrm{F}_{(1,19)}=8.23 ; p=0.0098\right)$, and time bin $\left(\mathrm{F}_{(27,513)}=5.81\right.$; $p<0.001)$. There was a drug $\times$ time bin interaction $\left(\mathrm{F}_{(27,513)}=8.27 ; p<0.001\right)$, but neither drug $\times$ genotype nor genotype $\times$ time bin interactions (both $\mathrm{F}<1 ; p>0.20$ ). There was, however, a drug $\times$ genotype $\times$ time bin interaction $\left(\mathrm{F}_{(27,513)}=2.00 ; p=0.002\right)$, indicating that wild-type and GRM $2 / 3^{-l-}$ mice responded differentially to $10 \mathrm{mg} / \mathrm{kg}$ amphetamine at different time points post-injection.

\section{Experiment 9: Injection Stress has Differential Effects on T-Maze SWM Performance in GRM2/3 $3^{-I-}$ Mice and Wild-Type Mice}

Finally, we examined whether an amphetamine-induced increase in arousal would affect spatial memory performance in the T-maze rewarded alternation task. A low dose $(0.5 \mathrm{mg} / \mathrm{kg})$ of amphetamine was used to avoid any risk of aphagia. A within-subjects analysis comparing performance after either amphetamine or saline injection revealed a main effect of genotype $\left(\mathrm{F}_{(1,21)}=6.24 ; p=0.02\right)$, as $\mathrm{GRM} 2 / 3^{-1-}$ mice performed less well than wild-type controls in both injection conditions. There was, however, no effect of drug condition (ie, amphetamine vs saline $-\mathrm{F}<1 ; p>0.2$ ), and no genotype $\times$ drug condition interaction $(\mathrm{F}<1 ; p>0.2)$.

Although the effects of $0.5 \mathrm{mg} / \mathrm{kg}$ amphetamine on SWM performance did not differ from those of saline, we observed that the injection stress itself differentially affected the performance of wild-type and GRM $2 / 3^{-1-}$ mice, producing impairment in the former but facilitating performance in the latter. We therefore performed a further comparison of 'injected' (including both saline and amphetamine data) vs 'no-injection' performance (including (i) the last day of training on the task before any injection and (ii) the final 

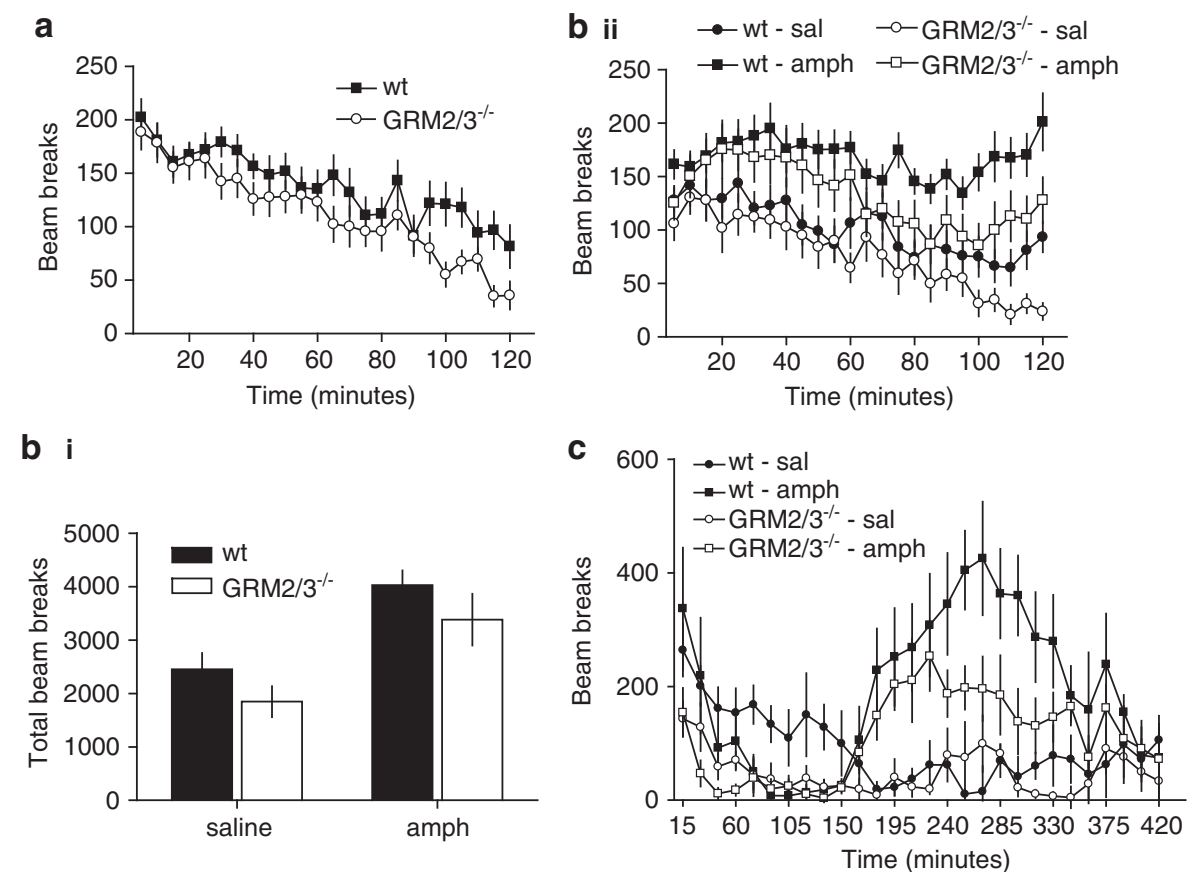

Figure $5 \mathrm{GRM} 2 / 3^{-1-}$ mice are hypoactive. (a) GRM2/3 ${ }^{-1-}$ mice $(n=14)$ displayed less spontaneous locomotor activity (LMA) than wild-type mice (wt; $n=18$ ). (b) In all, $2.5 \mathrm{mg} / \mathrm{kg}$ amphetamine increased LMA in both wild-type $(n=10)$ and GRM2/3 ${ }^{-1-}$ mice $(n=10)$ mice, such that GRM2/3 ${ }^{-1-}$ mice remained hypoactive relative to wild-types. (i) Summarizes the total number of beam breaks over a 2-h period while (ii) shows the time course of changes in LMA. (c) In total, $10 \mathrm{mg} / \mathrm{kg}$ amphetamine induced stereotypy in both wt $(n=6)$ and GRM $/ 3^{-1-}(n=6)$ mice, resulting in a decrease in LMA followed later by an increase in activity levels relative to saline-injected controls ( $n=5$ wt and $n=6 \mathrm{GRM} 2 / 3^{-1-}$ mice). At all-time points GRM2/3 ${ }^{-1-}$ mice were hypoactive relative to wild-types.

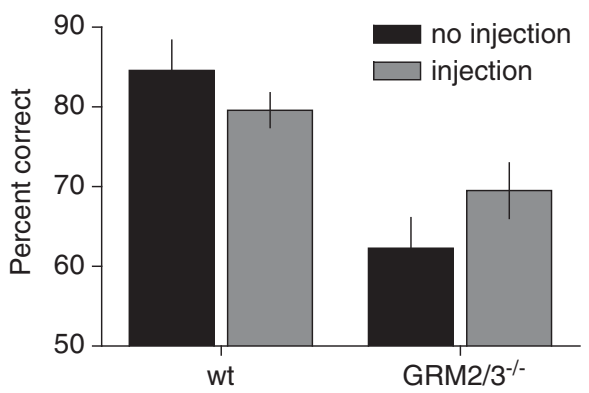

Figure 6 Effect of injection stress on the appetitive T-maze SWM task. Injection stress impaired performance in the wild-types ( $w t ; n=12$ ) but facilitated it in GRM2/3 $3^{-1-}$ mice $(n=11)$.

day of testing performed $24 \mathrm{~h}$ after the last injection). Thus, injected and no-injection performance were compared using a counterbalanced 'A-B-B-A' design (where ' $\mathrm{A}$ ' = no injection and ' $\mathrm{B}$ ' $=$ injected). This comparison revealed a main effect of genotype $\left(\mathrm{F}_{(1,21)}=18.95 ; p=0.0003\right)$, as GRM $2 / 3^{-l-}$ mice remained impaired overall relative to wild-types, but no main effect of condition (ie, injected $v s$ no-injection) $(\mathrm{F}<1 ; p>0.20)$. Importantly, however, there was a significant genotype $\times$ condition interaction $\left(\mathrm{F}_{(1,21)}=5.64\right.$; $p=0.027)$, indicating that the two groups were responding differentially to the injection stress. Simple main effects analysis showed that the opposite directions of changes in performance in wild-type $v s$ GRM $2 / 3^{-l-}$ mice post-injection were responsible for the significant interaction, as there was no significant effect of condition for either group individ- ually (wild-types: $\mathrm{F}_{(1,21)}=1.96 ; \quad p=0.18 ; \quad \mathrm{GRM}^{2} / 3^{-1-}$ : $\mathrm{F}_{(1,21)}=3.80 ; p=0.065$; Figure 6).

\section{DISCUSSION}

GRM $2 / 3^{-1-}$ mice demonstrated a novel fractionation of hippocampus-dependent spatial memory. They were impaired in appetitively motivated spatial tasks (experiments 1-3) but not in the aversively motivated open field water maze (experiment 4). This dissociation was confirmed using experimentally naïve mice in fully counterbalanced appetitive and aversive versions of the Y-maze SRM task (experiment 5). GRM2/3 $3^{-1-}$ mice were not impaired on all appetitively motivated tasks, however, displaying normal acquisition of a non-spatial, visual discrimination task (experiment 6). Furthermore, GRM2/3 ${ }^{-l-}$ mice showed reduced spatial memory for recently visited arms in a Y-maze test of spontaneous, spatial novelty preference that does not involve a food reward, but instead relies on animals' exploratory drive (experiment 7). Therefore, the deficits do not simply reflect reduced appetitive motivation for the milk reward. Instead, the pattern of results suggests a change in the arousal-cognition function in GRM2/3 $3^{-1-}$ mice. This fractionation of spatial memory in GRM2/3 $3^{-1-}$ mice is, to our knowledge unique. It is, for example, very different from the phenotypes seen in ionotropic glutamate receptor subunit knockout mice, which exhibit fractionated spatial memory on the basis of different aspects of information processing, rather than on the arousing properties of the experimental paradigms. For example, 
deletion of GluA1 (Reisel et al, 2002; Schmitt et al, 2003) or GluN2A (Bannerman et al, 2008) dissociate SWM from SRM.

A well-established inverted U-shaped function relates levels of acute stress and arousal with performance on cognitive tasks; that is, low levels of stress increase levels of attention and arousal, and enhances cognitive performance relative to the 'non-stressed' state. Above a certain threshold, however, higher levels of stress become deleterious (Yerkes and Dodson, 1908). By this account, on low stress, appetitive maze tasks, both groups likely sit on the rising phase of the inverted U-shaped function, with arousal levels in GRM2/3 $3^{-I-}$ mice hypothesized to be below those of wildtype animals, resulting in spatial memory deficits. During aversive tasks like the water maze, GRM $2 / 3^{-l-}$ mice move closer to the peak of the inverted $\mathrm{U}$ function, improving their performance and catching up with that of the controls. Importantly, injection stress also facilitated performance in GRM $2 / 3^{-1-}$ mice but actually impaired spatial memory performance in wild-type mice (experiment 9). Thus, injection stress also moved GRM $2 / 3^{-{ }_{-}}$mice to the right on the arousal-cognition function, but, at the same time, moved wild-type animals beyond the peak of the inverted $U$, thereby impairing their performance.

In keeping with the possibility of altered arousal levels in the GRM2 $/ 3^{-l-}$ mice, they displayed locomotor hypoactivity relative to wild-type controls, in both the absence and presence of amphetamine (experiment 8 ). Furthermore, in an assessment of diurnal activity levels across a 70-h period, the GRM $2 / 3^{-I-}$ mice were consistently less active during the middle of the dark phase. However, the relationship between activity levels and arousal is likely to be complex and it is notable that in a different situation, namely SWM testing on the T-maze, it might be argued that the GRM $2 / 3^{-I-}$ mice were more active than the wild-types, in demonstrating shorter running latencies on both sample and choice runs. Again, this may be consistent with a biphasic relationship between mGluR activity and behavior.

A role for mGluR2/3 activation in the inverted $U$-shaped relationship between arousal and cognition could, in addition to accounting for the results of this study, also accommodate previous, seemingly paradoxical, pharmacological data. Although the mGluR2/3 agonist LY354740 impaired T-maze rewarded alternation in normal animals (Aultman and Moghaddam, 2001), the same drug actually reversed the SWM performance deficit produced by PCP when co-administered on the same task (Moghaddam and Adams, 1998). At first glance, these opposing effects seem counter-intuitive. However, if under normal conditions for appetitive maze tasks, baseline glutamate, and arousal levels lie on the ascending limb of the inverted-U function, then an agonist-induced reduction in glutamate release would be expected to impair cognition (Aultman and Moghaddam, 2001; Gregory et al, 2003; Higgins et al, 2004; Sato et al, 2004; Lin et al, 2005; Daumas et al, 2009). Conversely, under circumstances of enhanced glutamate levels, as produced by PCP, (ie, to the right of the peak), then the mGluR2/3 agonist-induced reduction of glutamate (Moghaddam and Adams, 1998) would be predicted to improve cognitive performance (Aultman and Moghaddam, 2001). Of note, Marek et al, (2010) also recently postulated a biphasic doseeffect function between group II mGluRs and cognition. Our findings provide empirical support for the notion, and extend it by suggesting that arousal may be one of the mediating variables.

Although an 'inverted $U$ ' is an attractive model, it remains speculative. It will be important to identify the pathways and substrates by which the proposed interaction between arousal and cognition occurs, because the deficits in the GRM $2 / 3^{-1-}$ mice are unlikely to arise entirely from the hippocampus, nor solely from an effect on glutamate signaling. Thus, although the affected memory tasks are hippocampus-dependent, and it has been suggested that the hippocampus may be critical for the interplay between arousal and cognition (Gray and McNaughton, 2000), interconnected regions may also be involved. Group II mGluRs are expressed widely in limbic and forebrain regions (Gu et al, 2008). Notably, they may also have an important role in modulating arousal through effects on the ascending reticular activating system, and the associated midline and intralaminar thalamic nuclei. Within the thalamus, mGluR2 is preferentially expressed in these nuclei, and mGluR3 is relatively selectively expressed in GABAergic neurons of the reticular nucleus (Ohishi et al, 1993, 1998). Furthermore, a significant portion of neocortical group II mGluRs are on thalamocortical afferents (Marek et al, 2001). Thus, modulation of the reticular formation and associated thalamocortical pathways may be a prime target for mGluR modulation of arousal states.

Similarly, there may be downstream effects on other neurotransmitter systems beyond glutamate. Dopamine is one candidate, given its roles in hippocampal cognition (Lisman and Grace, 2005; Shohamy and Adcock, 2010) and in stress and arousal (Pani et al, 2000; Ungless et al, 2010). More specifically, group II mGluRs modulate dopamine release (Hu et al, 1999; Cartmell et al, 2000; Chaki et al, 2006; Pehrson and Moghaddam 2010), possibly with a biphasic dose relationship ( $\mathrm{Hu}$ et al, 1999). In addition, there are interactions between GRM3 and the dopaminemetabolizing enzyme catechol-O-methyltransferase, which affects working memory and cortical function (Tan et al, 2007). Indeed, dopamine has its own inverted U relationship with cognition, with dopaminergic manipulations, including response to amphetamine, having differential effects depending on the starting position on the curve (Arnsten, 1998; Mattay et al, 2003; Williams and Castner, 2006). It will be of interest to determine whether, and in what respect, the present findings reflect an overlap between the 'arousal' and 'dopamine' inverted U functions; preliminary data indicate changes in dopamine metabolism in the GRM $2 / 3^{-1-}$ mice (unpublished observations). Equally, other potential mediators of the putative altered arousalcognition relationship in GRM2/3 $3^{-1-}$ mice should not be overlooked, notably norepinephrine (Swanson et al, 2004; Lorrain et al, 2005; Nikiforuk et al, 2010), serotonin (Cartmell et al, 2000; Nikiforuk et al, 2010), and the HPA axis (Scaccianoce et al, 2003).

The main limitation of this study is that the generation of a sufficiently large number of double-knockout animals necessitated, for ethical and financial reasons, the use of separate breeding lines and thus non-littermate wild-type controls. This is a common practice in double-knockout mouse studies, but means that we cannot rule out the 
possibility that subtle differences in genetic background or epigenetic factors between GRM $2 / 3^{-/-}$and wild-type mice could have influenced the results. However, several considerations provide some reassurance in this regard: the findings were seen in several cohorts, including the replication of key results in animals arising from two different backcrosses, and the relatively large sample sizes and statistical significance of the key results. A second limitation is that we do not know the relative contributions of GRM2 and GRM3 to the findings. This information would help address some of the mechanistic questions raised above, given the differences in properties and functions of the two receptors (Harrison et al, 2008); however, repeating the present experiments in GRM2 $2^{-I-}$ and $\mathrm{GRM}^{-I-}$ mice might not prove conclusive, in light of the partial compensation that occurs in expression of the remaining receptor (Lyon et al, 2008). Further studies are also needed to determine whether the observed phenotype arises from the developmental consequences of the absence of group I1 mGluRs, and to clarify the downstream effects on other aspects of glutamate transmission.

Finally, our results have translational relevance for the range of disorders in which group II mGluRs have been implicated, and for which stress responsivity and motivation are important, such as anxiety, mood, and substance use disorders (Swanson et al, 2005; Witkin and Eiler, 2006; Markou, 2007). The greatest relevance, however, may be for schizophrenia (Moghaddam, 2004; Krystal et al, 2010), a disorder characterized not only by psychotic symptoms, but by disturbances in cognition, attention, and motivation. These various domains are sometimes simplistically considered in isolation, but are increasingly appreciated and conceptualized as being intertwined, and likely sharing overlapping substrates (eg, Kapur, 2003; Barch, 2005; Javitt, 2009). Our results suggest that group II mGluRs may be involved at the interface between these processes.

In summary, mice lacking group II mGluRs have impairments in appetitive but not aversive hippocampal memory tasks, and show a differential response to amphetamine and injection stress compared with wild-type mice. These findings suggest a change in the relationship between arousal and cognition, possibly explained in terms of an altered 'inverted U'. This attractive but speculative proposal, which was recently proposed in a more general form for the impact that stress has on glutamate pathways and thence memory function (Sandi, 2011), awaits refinement and critical testing. Such a model may help reconcile the seemingly conflicting results of studies using group II mGluR ligands, since their effects will likely be statedependent. Our findings also bear on the translational interest in group II mGluRs across a broad range of psychiatric disorders, all of which involve arousal, cognition, and their interplay.

\section{ACKNOWLEDGEMENTS}

This work was supported by a Wellcome Trust $\mathrm{PhD}$ studentship awarded to Louisa Lyon, and grants to David Bannerman from the Wellcome Trust (074385 and 087736). Additional support was from the UK Medical Research Council. We thank Professor Shigemoto Nakanishi for generous provision of $\mathrm{GRM} 2^{-l-}$ mice, used to produce the GRM $2 / 3^{-{ }_{-}}$mice.

\section{DISCLOSURE}

Mice were bred, genotyped, and supplied by GlaxoSmithKline under an unrestricted agreement with the University of Oxford, where all experiments were conducted. Dr Bannerman is a consultant to Eli Lilly and a member of their Centre for Cognitive Neuroscience. Dr Harrison in the last 3 years has received honoraria for lectures, chairing meetings, or advisory boards, from AstraZeneca, Bristol Myers Squibb, Janssen, Merck, Otsuka, and Wyeth. Drs Kew and Corti are employees of GlaxoSmithKline.

\section{REFERENCES}

Amitai N, Markou A (2010). Effects of metabotropic glutamate receptor $2 / 3$ agonism and antagonism on schizophrenia-like cognitive deficits induced by phencyclidine in rats. Eur $J$ Pharmacol 639: 67-80.

Arnsten AFT (1998). Catecholamine modulation of prefrontal cortical cognitive function. Trends Cogn Sci 2: 436-447.

Aultman JM, Moghaddam B (2001). Distinct contributions of glutamate and dopamine receptors to temporal aspects of rodent working memory using a clinically relevant task. Psychopharmacology 153: 353-364.

Bannerman DM, Niewoehner B, Lyon L, Romberg C, Schmitt WB, Taylor A et al (2008). NMDA receptor subunit NR2A is required for rapidly acquired spatial working memory but not incremental spatial reference memory. J Neurosci 28: 3623-3630.

Barch DM (2005). The relationships among cognition, motivation, and emotion in schizophrenia: how much and how little we know. Schizophr Bull 31: 875-881.

Cartmell J, Schoepp DD (2000). Regulation of neurotransmitter release by metabotropic glutamate receptors. J Neurochem 75: 889-907.

Cartmell J, Perry KW, Salhoff CR, Monn JA, Schoepp DD (2000). The potent, selective mGlu2/3 receptor agonist LY379268 increases extracellular levels of dopamine, 3,4-dihydroxyphenylacetic acid, homovanillic acid, and 5-hydroxyindole-3-acetic acid in the medial prefrontal cortex of the freely moving rat. J Neurochem 75: 1147-1154.

Chaki S, Yoshikawa R, Okuyama S (2006). Group II metabotropic glutamate receptor-mediated regulation of dopamine release from slices of rat nucleus accumbens. Neurosci Lett 404: $182-186$.

Creese I, Iversen SD (1974). The role of forebrain dopamine systems in amphetamine induced stereotyped behaviour in the rat. Psychopharmacologia 39: 345-357.

Daumas S, Ceccom J, Halley H, Frances B, Lassalle JM (2009). Activation of metabotropic glutamate receptor type $2 / 3$ supports the involvement of the hippocampal mossy fiber pathway on contextual fear memory consolidation. Learn Mem 16: 504-507.

de Quervain DJ, Papassotiropoulos A (2006). Identification of a genetic cluster influencing memory performance and hippocampal activity in humans. Proc Natl Acad Sci USA 103: 4270-4274.

Deacon RM, Bannerman DM, Kirby BP, Croucher A, Rawlins JN (2002). Effects of cytotoxic hippocampal lesions in mice on a cognitive test battery. Behav Brain Res 133: 57-68.

Egan MF, Straub RE, Goldberg TE, Yakub I, Callicott JH, Hariri AR et al (2004). Variation in GRM3 affects cognition, prefrontal 
glutamate, and risk for schizophrenia. Proc Natl Acad Sci USA 101: 12604-12609.

Ghose S, Gleason K, Potts B, Amezcua KL, Tamminga CA (2009). Differential expression of metabotropic glutamate receptors 2 and 3 in schizophrenia: a mechanism for antipsychotic drug action? Am J Psychiatry 166: 812-820.

Gonzalez-Maeso J, Ang RL, Yuen T, Chan P, Weisstaub NV, Lopez-Gimenez JF et al (2008). Identification of a serotonin/ glutamate receptor complex implicated in psychosis. Nature 452: 93-U9.

Gray JA, McNaughton N (2000). The Neuropsychology of Anxiety (2nd edn) Oxford University Press: Oxford.

Gregory ML, Stech NE, Owens RW, Kalivas PW (2003). Prefrontal group II metabotropic glutamate receptor activation decreases performance on a working memory task. Ann NY Acad Sci 1003: 405-409.

Gu G, Lorrain DS, Wei H, Cole RL, Zhang X, Daggett LP et al (2008). Distribution of metabotropic glutamate 2 and 3 receptors in the rat forebrain: Implication in emotional responses and central disinhibition. Brain Res 1197: 47-62.

Gupta DS, McCullumsmith R, Beneyto M, Haroutunian V, Davis KL, Meador-Woodruff JH (2005). Metabotropic glutamate receptor protein expression in the prefrontal cortex and striatum in schizophrenia. Synapse 57: 123-131.

Harrison PJ, Lyon L, Sartorius LJ, Burnet PWJ, Lane TA (2008). Metabotropic glutamate receptor 3 (mGluR3, mGlu3, GRM3): expression, function, and involvement in schizophrenia. J Psychopharmacol 22: 308-322.

Higgins GA, Ballard TM, Kew JN, Richards JG, Kemp JA, Adam G et al (2004). Pharmacological manipulation of mGlu2 receptors influences cognitive performance in the rodent. Neuropharmacology 46: 907-917.

Hu G, Duffy P, Swanson C, Ghasemzadeh MB, Kalivas PW (1999). The regulation of dopamine transmission by metabotropic glutamate receptors. J Pharmacol Exp Therap 289: 412-416.

Jarrard LE (1993). On the role of the hippocampus in learning and memory in the rat. Behav Neural Biol 60: 9-26.

Javitt DC (2009). When doors of perception close: bottom-up models of disrupted cognition in schizophrenia. Annu Rev Clin Psychol 5: 249-275.

Kapur S (2003). Psychosis as a state of aberrant salience: a framework linking biology, phenomenology, and pharmacology in schizophrenia. Am J Psychiatry 160: 13-23.

Krystal JH, Abi-Saab W, Perry E, D'Souza DC, Liu N, Georguieva R et al (2005). Preliminary evidence of attenuation of the disruptive effects of the NMDA glutamate receptor antagonist, ketamine, on working memory by pretreatment with the group II metabotropic glutamate receptor agonist, LY354740, in healthy human subjects. Psychopharmacology 179: 303-309.

Krystal JH, Mathew SJ, D’Souza DC, Garakani A, Gunduz-Bruce H, Charney DS (2010). Potential psychiatric applications of metabotropic glutamate receptor agonists and antagonists. CNS Drugs 24: $1-25$.

Lin CH, Lee CC, Huang YC, Wang SJ, Gean PW (2005). Activation of group II metabotropic glutamate receptors induces depotentiation in amygdala slices and reduces fear-potentiated startle in rats. Learn Mem 12: 130-137.

Lisman JE, Grace AA (2005). The hippocampal-VTA loop: controlling the entry of information into long-term memory. Neuron 46: 703-713.

Lorrain DS, Baccei CS, Correa LD, Bristow LJ (2005). Comparison of the effects of diazepam, the CRF1 antagonist CP-154,526 and the group II1 mGlu receptor agonist LY379268 on stress-evoked extracellular norepinephrine levels. Neuropharmacology 48: 927935.

Lyon L, Kew JN, Corti C, Harrison PJ, Burnet PW (2008). Altered hippocampal expression of glutamate receptors and transporters in GRM2 and GRM3 knockout mice. Synapse 62: 842-850.
Marek GJ, Behl B, Bespalov AY, Gross G, Lee Y, Schoemaker H (2010). Glutamatergic (N-methyl-D-aspartate receptor) hypofrontality in schizophrenia: too little juice or a miswired brain? Mol Pharmacol 77: 317-326.

Marek GJ, Wright RA, Gewirtz JC, Schoepp DD (2001). A major role for thalamocortical afferents in serotonergic hallucinogen receptor function in the rat neocortex. Neuroscience 105: 379-392.

Marenco S, Steele SU, Egan MF, Goldberg TE, Straub RE, Sharrief $\mathrm{AZ}$ et al (2006). Effect of metabotropic glutamate receptor 3 genotype on $\mathrm{N}$-acetylaspartate measures in the dorsolateral prefrontal cortex. Am J Psychiatry 163: 740-742.

Markou A (2007). Metabotropic glutamate receptor antagonists: novel therapeutics for nicotine dependence and depression? Biol Psychiatry 61: 17-22.

Mattay VS, Goldberg TE, Fera F, Hariri AR, Tessitore A, Egan MF et al (2003). Catechol O-methyltransferase val(158)-met genotype and individual variation in the brain response to amphetamine. Proc Natl Acad Sci USA 100: 6186-6191.

Moghaddam B (2004). Targeting metabotropic glutamate receptors for treatment of the cognitive symptoms of schizophrenia. Psychopharmacology 174: 39-44.

Moghaddam B, Adams BW (1998). Reversal of phencyclidine effects by a group II metabotropic glutamate receptor agonist in rats. Science 281: 1349-1352.

Moreno JL, Sealfon SC, Gonzales-Maeso J (2009). Group II metabotropic glutamate receptors and schizophrenia. Cell Mol Life Sci 66: 3777-3785.

Morris RG, Anderson E, Lynch GS, Baudry M (1986). Selective impairment of learning and blockade of long-term potentiation by an N-methyl-D-aspartate receptor antagonist, AP5. Nature 319: 774-776.

Murray TK, Ridley RM (1999). The effect of excitotoxic hippocampal lesions on simple and conditional discrimination learning in the rat. Behav Brain Res 99: 103-113.

Nicodemus KK, Kolachana BS, Vakkalanka R, Straub RE, Giegling I, Egan MF et al (2007). Evidence for statistical epistasis between catechol-O-methyltransferase (COMT) and polymorphisms in RGS4, G72 (DAOA), GRM3, and DISC1: influence on risk of schizophrenia. Hum Genet 120: 889-906.

Nikiforuk A, Popik P, Drescher KU, van Gaalen M, Relo A-L, Mezler M et al (2010). Effects of a positive allosteric modulator of group II metabotropic glutamate receptors, LY487379, on cognitive flexibility and impulsive-like responding in rats. J Pharmacol Exp Therap 335: 665-673.

Niswender CM, Conn PJ (2010). Metabotropic glutamate receptors: physiology, pharmacology, and disease. Annu Rev Pharmacol Toxicol 50: 295-322.

Ohishi H, Shigemoto R, Nakanishi S, Mizuno N (1993). Distribution of the mRNA for a metabotropic glutamate receptor (mGluR3) in the rat brain: an in situ hybridization study. J Comp Neurol 335: 252-266.

Ohishi H, Neki A, Mizuno N (1998). Distribution of a metabotropic glutamate receptor, mGluR2, in the central nervous system of the rat and mouse: an immunohistochemical study with a monoclonal antibody. Neurosci Res 30: 65-82.

Pani L, Porcella A, Gessa GL (2000). The role of stress in the pathophysiology of the dopamine system. Mol Psychiatry 5: $14-21$.

Patil ST, Zhang L, Martenyi F, Lowe SL, Jackson KA, Andreev BV et al (2007). Activation of $m G l u 2 / 3$ receptors as a new approach to treat schizophrenia: a randomized Phase 2 clinical trial. Nat Med 13: 1102-1107.

Pehrson AL, Moghaddam B (2010). Impact of metabotropic glutamate $2 / 3$ receptor stimulation on activated dopamine release and locomotion. Psychopharmacology 211: 443-455.

Reisel D, Bannerman DM, Schmitt WB, Deacon RM, Flint J, Borchardt $\mathrm{T}$ et al (2002). Spatial memory dissociations in mice lacking GluR1. Nat Neurosci 5: 868-873. 
Sanderson DJ, Gray A, Simon A, Taylor AM, Deacon RM, Seeburg PH et al (2007). Deletion of glutamate receptor-A (GluR-A) AMPA receptor subunits impairs one-trial spatial memory. Behav Neurosci 121: 559-569.

Sandi C (2011). Glucocorticoids act on glutamatergic pathways to affect memory processes. Trends Neurosci 34: 165-176.

Sartorius LJ, Weinberger DR, Hyde TM, Harrison PJ, Kleinman JE, Lipska BK (2008). Expression of a GRM3 splice variant is increased in the dorsolateral prefrontal cortex of individuals carrying a schizophrenia risk SNP. Neuropsychopharmacology 33: 2626-2634.

Sato T, Tanaka K, Ohnishi Y, Teramoto T, Irifune M, Nishikawa T (2004). Inhibitory effects of group II mGluR-related drugs on memory performance in mice. Physiol Behav 80: 747-758.

Scaccianoce S, Matrisciano F, Del Bianco P, Caricasole A, Gerevini VD, Cappuccio I et al (2003). Endogenous activation of group-II metabotropic glutamate receptors inhibits the hypothalamic-pituitary-adrenocortical axis. Neuropharmacology 44: 555-561.

Schlumberger C, Schafer D, Barberi C, More L, Nagel J, Pietraszek M et al (2009). Effects of a metabotropic glutamate receptor group II agonist LY354740 in animal models of positive schizophrenia symptoms and cognition. Behav Pharmacol 20: 56-66.

Schmitt WB, Deacon RM, Seeburg PH, Rawlins JN, Bannerman DM (2003). A within-subjects, within-task demonstration of intact spatial reference memory and impaired spatial working memory in glutamate receptor-A-deficient mice. $J$ Neurosci 23: 3953-3959.

Schoepp DD (2001). Unveiling the functions of presynaptic metabotropic glutamate receptors in the central nervous system. J Pharmacol Exp Ther 299: 12-20.

Shohamy D, Adcock RA (2010). Dopamine and adaptive memory. Trends Cogn Sci 14: 464-472.

Spinelli S, Ballard T, Gatti-McArthur S, Richards GJ, Kapps M, Woltering $\mathrm{T}$ et al (2005). Effects of the mGluR2/3 agonist LY354740 on computerized tasks of attention and working memory in marmoset monkeys. Psychopharmacology 179: 292-302.

Swanson CJ, Perry KW, Schoepp DD (2004). The mGlu2/3 receptor agonist, LY354740, blocks immobilization induced increases in noradrenaline and dopamine release in the rat medial prefrontal cortex. J Neurochem 88: 194-202.

Swanson CJ, Bures M, Johnson MP, Linden AM, Monn JA, Schoepp DD (2005). Metabotropic glutamate receptors as novel targets for anxiety and stress disorders. Nat Rev Drug Disc 4: 131-144.

Tan HY, Chen Q, Sust S, Buckholtz JW, Meyers JD, Egan MF et al (2007). Epistasis between catechol-O-methyltransferase and type II metabotropic glutamate receptor 3 genes on working memory brain function. Proc Natl Acad Sci USA 104: 12536-12541.

Ungless MA, Argilli A, Bondi A (2010). Effects of stress and aversion on dopamine neurons: Implications for addiction. Neurosci Biobehav Rev 35: 151-156.

Williams GV, Castner SA (2006). Under the curve: critical issues for elucidating D1 receptor function in working memory. Neuroscience 139: 263-276.

Witkin JM, Eiler WJ (2006). Antagonism of metabotropic glutamate group II receptors in the potential treatment of neurological and psychiatric disorders. Drug Dev Res 67: 757-769.

Yerkes RM, Dodson JD (1908). The relation of strength of stimulus to rapidity of habit formation. J Comp Neurol Psychol 18: 459-482.

Yokoi M, Kobayashi K, Manabe T, Takahashi T, Sakaguchi I, Katsuura $\mathrm{G}$ et al (1996). Impairment of hippocampal mossy fiber LTD in mice lacking mGluR2. Science 273: 645-647.

This work is licensed under the Creative Commons Attribution-NonCommercial-No Derivative Works 3.0 Unported License. To view a copy of this license, visit http://creativecommons.org/ licenses/by-nc-nd/3.0/

Supplementary Information accompanies the paper on the Neuropsychopharmacology website (http://www.nature.com/npp) 